\title{
A experiência com gás natural/GLP no polo gesseiro do Araripe, PE
}

\section{(Experience with natural gas/LPG in the plasterer polo Araripe, PE, Brazil)}

\author{
M. A. C. Oliveira ${ }^{1}$, A. H. Shinohara ${ }^{2}$ \\ ${ }^{1}$ Av. Santos Dumont 881, apto. 404, Rosarinho, Recife, PE 52041-060 \\ ${ }^{2}$ Departamento de Engenharia Mecânica, Centro de Tecnologia e Geociências, Universidade Federal de \\ Pernambuco R. Acadêmico Hélio Ramos s/n, Cidade Universitária, Recife, PE 50740-530
}

\begin{abstract}
Resumo
Gipsita, sulfato de cálcio dihidratado $\left(\mathrm{CaSO}_{4} \cdot 2 \mathrm{H}_{2} \mathrm{O}\right)$, encontrada no Polo Gesseiro do Araripe, Pernambuco, é considerada a de melhor qualidade no mundo, com teor de pureza variando de $88 \%$ a $98 \%$, contendo $79 \%$ de sulfato de cálcio e $21 \%$ de água de cristalização. Quando desidratada até a perda de 1,5 moléculas de água, constitui-se num hemidrato estável, denominado gesso, cujas características são a capacidade de rehidratação (reação exotérmica), o fenômeno de pega e o retorno à estrutura cristalina. O polo fornece $95 \%$ do gesso consumido no Brasil. As reservas são estimadas em 1,2 bilhões de toneladas, quinto volume do mundo. Os fornos do Polo podem ser de contato direto ou indireto entre os gases de combustão e o minério, e quanto ao tipo de funcionamento, batelada ou contínuo. No indireto, os gases aquecem uma superfície metálica que transfere o calor usando lenha ou óleo BPF, já que o contato dos mesmos com a gipsita não é recomendável, podendo ocorrer mistura do material, acarretando alteração das propriedades do gesso. No direto, o gás flui no interior de um cilindro metálico, permitindo maior eficiência na troca térmica. A utilização de gás natural traz vantagens como eficiência da troca térmica, maior volume de processamento e preservação do ecossistema, por ser pouco poluente. Sua combustão é limpa, isenta de fuligem e outros materiais que possam prejudicar o meio ambiente com baixos teores de nitrogênio, dióxido de carbono, água e compostos de enxofre. O gás natural chegou ao Araripe em março de 2011, numa experiência piloto, com expectativa de um salto de qualidade e de volume na produção local. Mais limpo e eficiente, poderá oferecer a segurança energética necessária para que o setor atenda melhor uma demanda crescente, evitando o desmatamento da região que usa a lenha como combustível.
\end{abstract}

Palavras-chave: gesso, gás natural, desmatamento, fornos de contato direto, preservação ambiental, polo gesseiro.

Abstract

Gypsum, calcium sulfate dihydrate $\left(\mathrm{CaSO}_{4} \mathrm{2H}_{2} \mathrm{O}\right)$ found in Polo Plasterer Araripe, Pernambuco, Brazil, is considered the best quality in the world, with purity content ranging from $88 \%$ to $98 \%$ containing $79 \%$ sulfate calcium and $21 \%$ water of crystallization. When dried until the loss of 1.5 water molecules, constitutes a stable hemihydrate, called plaster, whose features are the ability to rehydrate with exothermic reaction, the phenomenon handle and return to the crystal structure. Polo provides $95 \%$ of the plaster consumed in Brazil. The reserves are estimated at 1.2 billion tons, the world's fifth volume. Ovens Pole can be direct or indirect contact between the flue gas and ore, and the type of operation, batch or continuous. In the indirect gas heat a metallic surface that transfers the heat using fuel or bunker oil, since the contact thereof with the gypsum is not recommended and mixture of the material may occur, resulting in alteration of properties of the plaster. In direct, the gas flows inside a metal cylinder, allowing more efficient heat exchange. The use of natural gas has advantages such as heat exchange efficiency and higher volume processing and preservation of the ecosystem, being low-polluting. Its combustion is clean, free of soot and other materials that can harm the environment with low levels of nitrogen, carbon dioxide, water and sulfur compounds. Natural gas reached Araripe in March 2011, a pilot experiment, with the expectation of a jump in quality and volume on local production. Cleaner and more efficient, can provide energy security required for the sector to better meet growing demand, avoiding deforestation in the region that uses wood as fuel. Keywords: gypsum, natural gas, deforestation, ovens direct contact, environmental preservation, polo plasterer.

\section{INTRODUÇÃO}

O gás natural é um combustível fóssil que se encontra na natureza, normalmente em reservatórios profundos no subsolo, associado ou não ao petróleo. Assim como o petróleo, ele resulta da degradação da matéria orgânica, dominantemente de origem algálica, afora fósseis de animais e plantas pré-históricas, sendo retirado da terra através de perfurações. Inodoro, incolor e de queima mais limpa que os demais combustíveis, o gás natural é resultado da combinação de hidrocarbonetos gasosos, nas condições normais atmosféricas de pressão e temperatura, contendo, principalmente, metano e etano [1].

Gás natural associado: o gás Natural associado é aquele que, em reservatórios, se encontra dissolvido em óleo ou se apresenta como uma "capa" de gás. Este tipo de gás, antes de ser distribuído, precisa ser separado do óleo.

Gás natural não-associado: o gás natural não-associado é aquele que, em reservatórios, se encontra livre de óleo ou apresenta pequena quantidade deste componente. Este tipo de gás é de mais fácil comercialização, já que não é necessário um processo para separação de componentes. 
Ocorrência e distribuição: há campos petrolíferos da bacia Potiguar que produzem gás - Macau, Serra, Guamaré, Benfica e Riacho da Forquilha - cujo tratamento inicial nas estações coletoras e de separação de fluidos, resulta, adicionalmente, na melhoria da interação fluidodinâmica, com o envio dos fluidos para a UTPF - Unidade de Tratamento e Processamento de Fluidos, em Guamaré-RN, donde procedem os dois grandes gasodutos do Nordeste: o Nordestão, com cerca de $250 \mathrm{~km}$, destinado ao Distrito Industrial do Cabo, na Região Metropolitana do Recife e o GASFOR que se destina ao Distrito Industrial de Fortaleza. Oportuno chamar a atenção para a importância desses dois gasodutos na integração energética produzida pela Petrobrás, quando viabiliza a existência da Termoassu, responsável pela produção de vapor d’água, cuja injeção, cíclica ou contínua, vem viabilizando a produção de petróleo nos campo de Alto do Rodrigues, Estreito e adjacentes, além de disponibilização de reserva energética.

No dia 21 de dezembro de 2009 foi concluída, a instalação de um gasoduto entre Recife e Caruaru, no agreste pernambucano. As obras tiveram início em 2004, e o gasoduto tem uma extensão de $120 \mathrm{~km}$ e uma tubulação de 12 polegadas capaz de transportar um milhão de metros cúbicos por dia. Portanto adiciona-se a essa distância, totalizando quase 400 $\mathrm{km}$ de gasoduto. As indústrias localizadas nas cidades por onde ele passa, serão as primeiras beneficiadas, mas em um segundo momento, o gás chegará aos consumidores finais, como os donos de carros movidos pelo combustível e até as residências. $\mathrm{O}$ investimento total na obra foi de $\mathrm{R} \$ 116$ milhões. "A idéia é dar competitividade ao interior, para conseguir atingir o objetivo de gerar emprego e oportunidades de trabalho, fazendo com que Pernambuco seja um Estado mais equilibrado", disse, na inauguração, o governador de Pernambuco. A estação de redução de pressão de gás está instalada, no Distrito Industrial de Caruaru, no agreste de Pernambuco, onde funcionará a Central de Distribuição de Gás, que teve a pedra fundamental também implantada. Além da inauguração, foi assinada a lei de isenção do Imposto sobre Circulação de Mercadorias e Prestações de Serviços para as cidades do Sertão, onde as tubulações ainda não chegaram. De acordo com o governador, a retirada da tributação vai servir para compensar o frete dos caminhões que poderão se abastecer em Caruaru, a Capital do Forró e utilizar as rodovias para distribuir o produto. "Os veículos vão ser abastecidos em Caruaru e sairão pelas rodovias até o Sertão do Araripe, onde tem várias empresas que utilizam lenha, combustível proibido", explicou. De acordo com o governador, as carretas seriam abastecidas no município caruaruense a partir da primeira semana de fevereiro de 2010, quando ficaria pronta a central de distribuição da Copergás.

Distribuição: antes de ser distribuído por gasodutos, o gás natural passa por uma unidade de processamento, na qual são retiradas impurezas como água, outros gases e areia, além de componentes condensáveis e mais pesados, como gasolina natural e o gás liquefeito do petróleo (GLP ou "gás de cozinha"). As reservas de gás natural no Brasil são amplas
Tabela I - Composições típicas do gás natural. [Table I - Typical composition of natural gas.]

\begin{tabular}{cccc}
\hline Componentes & $\begin{array}{c}\text { Gás } \\
\text { Associado } \\
\% \text { molar }\end{array}$ & $\begin{array}{c}\text { Gás Não } \\
\text { Associado } \\
\% \text { molar }\end{array}$ & $\begin{array}{c}\text { Gás } \\
\text { processado } \\
(\%) \text { molar }\end{array}$ \\
\hline Metano & 68,46 & 81,78 & 86,18 \\
Etano & 10,53 & 8,38 & 9,51 \\
Propano+ & 7,37 & 3,14 & 1,01 \\
Butanos & 4,21 & 0,84 & 0,00 \\
Pentanos & 2,11 & 0,63 & 0,00 \\
Hexanos & 1,05 & 0,42 & 0,00 \\
Heptanos & 0,84 & 0,21 & 0,00 \\
Octanos & 0,53 & 0,10 & 0,00 \\
Superiores & 0,47 & 0,10 & 0,00 \\
Nitrogênio & 2,37 & 2,36 & 1,35 \\
Gás & 1,32 & 1,31 & 1,25 \\
Carbônico & & 0,73 & 0,70 \\
Água & 0,74 & 0
\end{tabular}

Obs.: Essa composição pode variar a partir do reservatório onde o gás é encontrado. Fonte: Dados fornecidos pelo acompanhamento de processos da Petrobrás/E\&P - RNCE, 2004.

e novas reservas estão sendo descobertas, o que garante o abastecimento em todo o território brasileiro por muito tempo.

\section{PRINCIPAIS PROPRIEDADES FÍSICO-QUÍMICAS}

Toxicidade: como mostra a sua composição molar, não existe nenhum componente tóxico no gás natural. No entanto, a presença do gás natural em grandes quantidades em ambientes fechados pode produzir afogamento por deslocamento de oxigênio.

Odor: o gás natural não apresenta odor nenhum em seu estado natural, que corresponde ao modo como ele é transportado. Não se deve confundir com o gás GLP (Gás Liquefeito de Petróleo, mais conhecido como gás de cozinha), que é aromatizado artificialmente como medida de segurança.

Poder calorífico do gás natural: o poder calorífico dos gases quantifica a sua capacidade de gerar energia, uma vez efetuada a combustão. Os gases com maior capacidade calórica são os mais pesados, sendo, no entanto mais instáveis e perigosos.

A Tabela abaixo mostra também os poderes caloríficos de outros combustíveis, para efeitos de comparação [1].

Tabela II - Poder calorífico de alguns combustíveis. [Table II - Calorific some fuels.]

\begin{tabular}{ll}
\hline Tipo de gás & Poder Calorífico \\
\hline Gás natural & $1.000-1.100 \mathrm{BTU} / \mathrm{ft} 3$ \\
Gasolina & $4.750 \mathrm{BTU} / \mathrm{ft} 3$ \\
GLP (gás de cozinha) & $2.500 \mathrm{BTU} / \mathrm{ft} 3$ \\
\hline
\end{tabular}


Alguns exemplos de materiais e seus poderes caloríficos:

Tabela III - Poderes caloríficos de alguns materiais. [Table III - Calorific some materials.]

\begin{tabular}{ccc}
\hline & $\begin{array}{c}\text { PCS } \\
\left(\mathrm{kWh} / \mathrm{m}^{3}\right)\end{array}$ & $\begin{array}{c}\text { PCI } \\
\left(\mathrm{kWh} / \mathrm{m}^{3}\right)\end{array}$ \\
\hline Gás natural & 10.274 & 9.054 \\
Eucalipto & 4.531 & - \\
(Eucaliptus urophylla) [1] & 4.750 & - \\
B. vulgaris vittata [1] &
\end{tabular}

PCS - Poder Calorifico Superior; PCI - Poder Calorifico Inferior

Produção de gesso: necessidade de energia térmica: o gesso $\left(\mathrm{CaSO}_{4} \cdot 0,5 \mathrm{H}_{2} \mathrm{O}\right)$ é um dos mais antigos materiais de construção e revestimento fabricados pelo Homem, como a cal e a terracota. Sua obtenção, a partir do minério de gipsita $\left(\mathrm{CaSO}_{4} \cdot 2 \mathrm{H}_{2} \mathrm{O}\right)$, consiste num aquecimento desse minério a $160{ }^{\circ} \mathrm{C}$ e uma posterior redução a pó. A gipsita quando aquecida sofre sucessivas perdas de água de cristalização. Se a taxa de aquecimento for próxima a $10^{\circ} \mathrm{C} / \mathrm{min}$, apresenta duas transformações endotérmicas entre 100 e $200{ }^{\circ} \mathrm{C}$ (na primeira perde $75 \%$ da sua água de cristalização, transformando-se num hemidrato, e na segunda perde os $25 \%$ restantes de água de cristalização, transformando-se em anidrita). Entre 200 e $1200{ }^{\circ} \mathrm{C}$, só se registra uma exoterma entre 380 e 450 ${ }^{\circ} \mathrm{C}$ (transformação polimórfica), entretanto muitas amostras de minérios de gipsita apresentam efeitos térmicos acima de $450{ }^{\circ} \mathrm{C}$, causados pela presença de impurezas, tais como argilominerais e carbonatos [2]. Encontra a sua maior aplicação na indústria da construção civil (revestimento de paredes, placas, blocos, painéis, etc.) onde pode substituir outros materiais como a cal, o cimento, a alvenaria e a madeira. É também muito utilizado na confecção de moldes para as indústrias cerâmica, metalúrgica e de plásticos; em moldes artísticos, ortopédicos e dentários; como agente desidratante; como aglomerante do giz e na briquetagem do carvão. Por sua resistência ao fogo é empregado na confecção de portas corta fogo; na mineração de carvão para vedar lâmpadas, engrenagens e áreas onde há perigo de explosão de gases. Isolantes para cobertura de tubulações e caldeiras são confeccionados com uma mistura de gesso e amianto, enquanto isolantes acústicos são produzidos com a adição de material poroso ao gesso [3].

Desde os anos da década de 1960 que Pernambuco assumiu, e vem mantendo, a posição de maior produtor nacional de gipsita e gesso. Isto pode ser explicado pelo fato das suas minas apresentarem melhores condições de lavra (menor razão estéril/minério, benéfica à sua mineração e maior pureza do minério); mais adequada infraestrutura (fácil acesso, vias de escoamento asfaltadas e disponibilidade de energia elétrica); e ainda, uma maior proximidade do mercado consumidor do que as da maioria dos outros Estados produtores.

A região produtora, que recebeu a denominação de Polo Gesseiro do Araripe, situa-se no extremo oeste do Estado, a cerca de $700 \mathrm{~km}$ da capital, Recife, e abrange os Municípios de Araripina, Bodocó, Exú, Ipubí, Ouricuri e Trindade, que representam 8,69\% do território do Estado e 2,98\% da população. As reservas estimadas do Polo Gesseiro do Araripe são da ordem de um bilhão de toneladas de minério bruto, representando $18 \%$ das jazidas do País. A produção de 2,6 milhões de toneladas/ano representa $95 \%$ de todo o gesso brasileiro, gerando 12.000 empregos diretos e mais de 60.000 empregos indiretos. São 332 empresas, sendo 26 mineradoras, 72 calcinadoras e 234 fábricas de prémoldados. A produção anual de gesso do Polo é dividida da seguinte forma: $61 \%$ para fabricação de blocos e placas, $35 \%$ para revestimento, $3 \%$ para moldes cerâmicos e $1 \%$ para outros usos. O alto teor de pureza, acima de $93 \%$, as características do clima tropical semi-árido com baixa umidade relativa e a mineração a céu aberto e uma matriz energética ajustada às condições atuais necessárias à obtenção de uma alta produtividade e cuidados com o meio ambiente permitiriam ao Pólo a preparação de uma gama de produtos de alta qualidade tecnológica [4].

A utilização do gás natural oferece importantes vantagens em relação aos combustíveis convencionalmente (lenha e óleo BPF) utilizados no Polo Gesseiro do Araripe. O seu uso assegura uma alta eficiência térmica para o processo de contato direto, não gerando contaminações no produto final e reduz consideravelmente os níveis de poluição ambiental.

\section{MATERIAS E MÉTODOS}

Gás Natural/GLP no Polo Gesseiro do Araripe: a chegada, ainda como projeto-piloto, do gás natural ao "Chapadão do Araripe", em abril de 2011, no extremo oeste de Pernambuco, aumenta as expectativas de crescimento do polo gesseiro em quatro municípios da região. Cerca de $95 \%$ do gesso consumido no Brasil, algo em torno de 5 milhões de toneladas por ano, vêm dessa área. $\mathrm{O}$ dinamismo da construção civil já acelerou a procura pelo gesso, mas as cidades do polo e as empresas sofrem com problemas de infraestrutura. Praticamente todas as fábricas se abastecem de lenha e coque. $O$ gás natural chegou em 24.3.2011, ao Araripe. O abastecimento foi feito por meio de carretas e fez parte de um projeto piloto da Companhia Pernambucana de Gás, que pretende mudar a matriz energética no polo gesseiro, atualmente $95 \%$ baseada na lenha. O gás natural é apontado como o único combustível capaz de aliar a sustentabilidade ambiental e o menor custo na produção do gesso. Inicialmente, apenas uma indústria recebeu o gás. A proposta era estimular as indústrias a optarem pelo gás natural, a partir da experiência do projeto piloto. $\mathrm{O}$ gás natural, mais limpo e eficiente, pode ajudar o setor a atender melhor a demanda, que em 2010 avançou $30 \%$. Como todo polo industrial tipicamente brasileiro, o "Chapadão do Araripe" é um vai e vem frenético de caminhões de todas as partes do país; estes carregam basicamente madeira, coque de petróleo e gesso nas mais variadas formas. Várias alternativas vêm sendo estudadas para levar o gás para o maior polo gesseiro do país, em Araripina, como a ampliação do gasoduto, que hoje 
termina em Caruaru. Mas para fazer um gasoduto, seria preciso uma demanda contratada de pelo menos $200 \mathrm{mil} \mathrm{m}^{3}$ por dia, afirmou o presidente da Copergás, Aldo Guedes. Enquanto a interligação não sai do papel, a alternativa é apostar no abastecimento através de carretas. O projeto foi anunciado em 2010, mas só em 2011 foi concretizado. Esse transporte por carretas foi terceirizado dependendo do interesse de distribuidoras por esse mercado. O pontapé inicial foi dado pela White Martins. A CDGN começou a construir a sua base em Caruaru e também vai levar o gás para o Sertão. Para compensar o custo com frete, compressão do gás em Caruaru e descompressão no Araripe, o governo de Pernambuco isentou a alíquota de 17\% de ICMS sobre o combustível para as áreas aonde o gás não chega por gasoduto. "A expectativa é que o gás chegasse a um preço entre $\mathrm{R} \$ 1,10$ e $\mathrm{R} \$ 1,30$ por $\mathrm{m}^{3 \text { ", }}$, disse Alexandre Arraes, dono da Newgipso, que foi a primeira empresa a operar com gás natural no Araripe, com demanda de $2 \mathrm{mil} \mathrm{m}^{3}$ por dia. A fábrica de médio porte se localiza no distrito industrial do município de Araripina. $\mathrm{O}$ fornecimento, porém, ocorreu apenas como projeto piloto do governo estadual, que está elaborando um modelo de negócio, baseado em isenções fiscais, para tornar economicamente viável a entrega do gás por caminhões enquanto um gasoduto não é construído, o que não tem prazo para acontecer. Nas primeiras experiências, o gás chegou à fábrica $30 \%$ mais barato do que o equivalente em madeira, segundo informou Aldo Guedes, presidente da Companhia Pernambucana de Gás, empresa controlada pelo governo de Pernambuco em sociedade com Petrobrás e Mitsui. A meta era operacionalizar pelo menos $30 \mathrm{mil}$ $\mathrm{m}^{3}$ por dia até o fim de 2011. A demanda, porém, é bem superior. Está hoje na casa de $300 \mathrm{mil} \mathrm{m}^{3}$ diários e só tende a crescer, dado que muitas novas empresas estão chegando, atraídas pelo horizonte promissor. Como incentivo, a conversão do forno foi subsidiada pela Copergás. O mesmo seria feito em fornos das indústrias Supergesso e SW Gesso, que somariam um consumo de $8 \mathrm{mil} \mathrm{m}^{3} / \mathrm{dia}$. A segunda fase do projeto seria conquistar mais 25 empresas e $54 \mathrm{mil} \mathrm{m}^{3}$ em contratos até 2012. Em seguida, chegar a 50 empresas, com consumo de $94 \mathrm{mil} \mathrm{m}^{3}$. Para finalmente, chegar a $200 \mathrm{mil} \mathrm{m}^{3}$ até 2016. Formado pelos municípios de Araripina, Trindade, Ipubi, Bodocó e Ouricuri, o polo gesseiro do Araripe, no extremo oeste pernambucano, fornece nada menos que $95 \%$ do gesso consumido no Brasil, algo hoje em torno de 5 milhões de toneladas por ano. As reservas de gipsita, rocha mineral que origina o gesso, são estimadas em 1,2 bilhão de toneladas, quinto maior volume do mundo, depois de Irã, China, Canadá e México. O crescimento da construção civil nacional acelera a demanda e alimenta os sonhos de grandeza da região, que sofre com gargalos importantes de infraestrutura, sobretudo em energia e transportes. Praticamente todas as fábricas do Polo abastecem com lenha e coque os fornos onde a gipsita é convertida no gesso em pó que conhecemos. Pleito antigo do setor, formado majoritariamente por pequenas e médias empresas, o gás natural começou a chegar ao Araripe, em abril de 2011, provocando grande expectativa de um salto de qualidade e de volume na produção local. Mais limpo e eficiente, o combustível poderá oferecer a segurança energética necessária para que o setor atenda melhor uma demanda que em 2010 avançou 30\% sobre o ano anterior. "Resolvendo a questão energética e logística, o crescimento é inevitável. O momento é de grande otimismo", afirmou o vice-presidente do Sindicato da Indústria do Gesso (Sindusgesso). Além da expansão do consumo per capita no Brasil, ainda pequeno se comparado a países como Argentina e Chile, o dirigente quer ver o gesso nacional forte no mercado externo. Do R \$ 1,6 bilhão que o setor deve faturar neste ano, menos de $1 \%$ virá de exportações. Por ser limpo, o gás natural pode ser injetado e queimado dentro do forno, acelerando o processo de calcinação da gipsita, que nada mais é do que a extração do excedente de água. Usando lenha, coque ou óleo combustível, altamente poluidor, a queima é feita fora do forno, para evitar a contaminação do gesso, o que torna o processo menos eficiente. "Com gás produziram-se quatro toneladas em uma hora; com lenha se gasta o dobro do tempo", afirmou o gerente de produção da New Gipso. A avaliação é semelhante na Ingenor, uma das maiores fabricantes da região, onde são queimadas mais de 450 toneladas de coque por mês. "Além da questão ambiental, a vantagem está no custo final do produto, porque o aproveitamento calórico do gás é de quase $100 \%$, enquanto que a transferência de calor que ocorre com o coque gera perdas importantes", explicou o responsável pela unidade. Por todo o polo se vê imensas montanhas de lenha, material que ainda responde por $90 \%$ da fonte energética das fábricas. Com o endurecimento da fiscalização ambiental sobre o corte da madeira nativa da caatinga, os fabricantes têm que trazer o combustível do Piauí e do Ceará, onde adquirem a lenha resultante da poda de cajueiros e goiabeiras. Apesar disso, ainda é corriqueira a utilização de madeira ilegal, segundo relatos dos empresários locais. Em áreas urbanas, grandes quantidades de compostos químicos são emitidas para a atmosfera pelas indústrias, veículos e decorrentes de outras atividades humanas. Perto de 3000 diferentes compostos provenientes da ação humana já foram identificados na atmosfera, sendo a maior parte deles orgânicos. Essa mistura complexa de poluentes causa preocupação devido ao impacto que pode causar à saúde e ao ambiente. Dessa forma, a determinação sistemática da qualidade do ar deve ser, por questões de ordem prática, limitada a um restrito número de poluentes, definidos em função de sua importância e dos recursos materiais e humanos disponíveis para determiná-los.

De uma forma geral, a escolha recai sempre sobre um grupo de poluentes que servem como indicadores de qualidade do ar, que são regulamentados e de uso universal: dióxido de enxofre $\left(\mathrm{SO}_{2}\right)$, material particulado (MP), monóxido de carbono (CO), ozônio $\left(\mathrm{O}_{3}\right)$ e óxidos de nitrogênio (NOx). A razão dessa escolha está relacionada a freqüência de ocorrência e aos efeitos adversos sobre o ambiente. Assim, os efeitos da poluição do ar podem ser 
caracterizados pela alteração de condições consideradas normais e pela potencialização de problemas já existentes, que podem se manifestar na saúde, no bem estar da população, na vegetação, na fauna, e sobre os materiais. Contudo, a atenção das autoridades e dos pesquisadores não deve se voltar apenas aos padrões de qualidade do ar, porque existem compostos que apesar de não serem regulamentados merecem atenção devido aos danos que causam ao ambiente e, principalmente, à saúde. Por isso, muita atenção tem sido dada às emissões veiculares de Compostos Orgânicos Voláteis (COV) e ao material particulado. Em áreas urbanas, os COV emitidos pelos veículos são importantes porque muitos deles são altamente reativos e interferem na química da atmosfera. Por outro lado, o estudo das partículas também é de interesse, pois elas exercem um papel relevante para a vida e envolvem vários domínios do conhecimento. As partículas: agem como núcleo de condensação de nuvens, podendo modificar o clima em escala local e global, bem como afetar a visibilidade atmosférica; podem absorver ou espalhar a radiação solar, com efeitos potencialmente significativos para o aquecimento global; representam superfícies ativas sobre as quais ocorrem reações químicas e fotoquímicas atmosféricas; em suspensão na atmosfera, têm influência sobre a saúde humana, através de mecanismos diretos ou indiretos de atuação. Apesar dos inúmeros estudos epidemiológicos, existem ainda dificuldades na identificação da origem das partículas; são transportadoras de substâncias poluentes para ecossistemas terrestres e aquáticos, assim como realizam o transporte desses materiais a longas distâncias, tendo um papel importante no balanço geoquímico, na disseminação da poluição e na deposição efetiva de partículas sobre o solo e a água [5].

Outra demanda antiga, o transporte do gesso também vislumbra dias melhores. Isso porque uma das principais atribuições da ferrovia Transnordestina será atender o polo do Araripe, o que deve gerar uma redução expressiva nos custos de frete. Levar o gesso a preços competitivos até o porto de Suape (PE) ou até Pecém (CE) pode representar uma nova chance para o setor competir no mercado externo, além de abastecer com mais eficiência a demanda nacional, que não se resume à construção civil. Agricultura, indústria cerâmica e ortopedia também são clientes relevantes. Em 1999, baseada em um projeto do Ministério dos Transportes, a CFN planejou construir uma ferrovia, com a extensão de $523 \mathrm{~km}$, denominada Transnordestina, a ser implantada em três etapas: $231 \mathrm{~km}$ ligando as cidades de Petrolina e Salgueiro, em Pernambuco; 113 km até Missão Velha, e daí $179 \mathrm{~km}$ até Cratéus, ambos no estado do Ceará. A Transnordestina foi projetada devido à importância do transporte ferroviário para o desenvolvimento econômico, social e ambiental sustentável da região. A ferrovia poderá permitir, ainda, a integração do sistema hidroviário do rio São Francisco o sistema rodoviário do sertão e o sistema ferroviário já existente, contribuindo para tornar o transporte de cargas mais eficiente, dinamizando a atividade econômica nas áreas próximas, por meio do aumento da geração de emprego e renda. Incluída entre as três maiores obras privadas do País - ao lado das hidrelétricas de Santo Antônio e Jirau, no Rio Madeira, em Roraima - a Transnordestina, após a sua conclusão (prevista para 2013), terá $1.728 \mathrm{~km}$ de extensão e ligará dois terminais portuários, o de Pecém, no Ceará, e o de Suape, em Pernambuco, ao sertão do Piauí, fazendo o transporte de aproximadamente 25 milhões de toneladas/ano de grãos, minérios e gesso, além de uma série de outros produtos, com o objetivo de aumentar a competitividade da produção agrícola e mineral da região, buscando uma integração contínua e acelerada da estrutura produtiva do Nordeste com as demais regiões do País [6]. A primeira previsão era de que a ferrovia, no trecho Piauí-Pernambuco, seria inaugurada em 2010. O trecho Piauí-Ceará ficaria pronto em 2013.

Nada disso aconteceu. Foi dado um novo prazo, 2012, que se encerrou sem que a obra tenha alcançado nem sequer $20 \%$ do trajeto. A nova previsão passou a ser dezembro de 2014. Enquanto gasoduto e trilhos seguem engessados, o caminhoneiro gaúcho Osni Rodrigues se prepara para mais uma jornada de 2,8 mil quilômetros entre Araripina e Porto Alegre. Na caçamba, 31 toneladas de placas de gesso que vão adornar casas, apartamentos e escritórios da capital gaúcha. Em março de 2012 a Indústria de Gessos Especiais (IGE), iniciou uma série de testes com o Gás Natural num volume de $60.000 \mathrm{~m}^{3}$, o que representou aproximadamente 11 carretas. O gás foi fornecido pela Copergás, sem custos para a IGE. O presidente da IGE, Josias Inojosa Filho nos informou sobre os detalhes desta experiência e nos forneceu algumas tabelas com importantes dados e resultados. Utilizou-se o gás em forma de testes do forno marmita rotativa horizontal, por batelada, da fabricante francesa Grelbex, com capacidade de 150 toneladas de gesso por dia de $24 \mathrm{~h}$. Foram quatro meses de testes com o gás natural e depois com o GLP. A mudança para o GLP no forno tipo marmita horizontal de queima indireta não foi tão simples. Foram necessários vários dias realizando diversas mudanças, desde a fornalha como o posicionamento dos queimadores, sistema de trocador de calor, aumento de ar de combustão no queimador, cronoanálise e melhoria no processo em relação aos tempos de ciclo. O Preço do GLP considerado de $\mathrm{R} \$ 2,08$, com o crédito dos impostos, já que o GLP entra na produção como insumo, reduz para $\mathrm{R} \$ 1,43$ / kg. No final dos testes em Setembro/2012, o consumo já foi bem menor, chegando a $17 \mathrm{~kg}$ de GLP por tonelada, que deu cerca de $\mathrm{R} \$ 24,31 /$ ton. em custo, o que tornava o valor bem viável. O problema estava no desembolso financeiro que não facilitava o fluxo de caixa, pois tínhase que pagar todos os impostos na compra do GLP para depois nos creditar, afirmou o presidente da IGE. O mesmo $17 \mathrm{~kg} /$ ton, representava um desembolso de $\mathrm{R} \$ 35,36 /$ ton de gesso. Atualmente a empresa elabora um estudo com a Supergasbras para tentar viabilizar a partir de isenção do ICMS com o estado de Pernambuco, uma vez que se trata de insumo onde se obtem crédito, porque sairia da base de Suape, PE, que tem o ICMS de $17 \%$. No caso da Ultragás, o 
ICMS era de $12 \%$ e não seria possível a isenção do imposto noutro estado. Em relação ao óleo combustível de bunker de navio, que está chegando a $\mathrm{R} \$ 0,85 / \mathrm{kg}$ e o consumo é de cerca de $27 \mathrm{~kg} /$ ton de gesso, o custo de produção fica por $\mathrm{R} \$ 22,95$. Entretanto tem-se que levar em consideração a sujeira do óleo combustível, o entupimento de queimadores, a queima não limpa, a dificuldade no manuseio, a variação da qualidade e o desgaste dos equipamentos que exige mais manutenção, além da questão ambiental. No fim fica mais caro o óleo cerca de $\mathrm{R} \$ 4,80$ /ton, o que é um valor estimado, somente em função da manutenção. A empresa não tem ainda experiência com o uso da madeira em seus fornos. Está modificando seu sistema para testar com madeira picada. O preço da madeira picada na região está chegando por cerca de $\mathrm{R} \$ 170,00 /$ ton. Considerando que 1 ton de madeira tem cerca de 4,1 steri tem-se informação de que algumas empresas estão usando cerca de 0,5 steri, outras dizem consumir cerca de 0,3 steri; logo o preço da madeira picada varia de $\mathrm{R} \$ 20,73 /$ ton a $\mathrm{R} \$ 12,44 /$ ton de gesso. Com o GN o melhor consumo foi de $23 \mathrm{~m}^{3} /$ ton no modelo de forno da indústria em questão. Levando em consideração que o preço do GN comprimido seria de $\mathrm{R} \$ 0,76 / \mathrm{m}^{3}$ e que o frete era de $\mathrm{R} \$ 1,20 / \mathrm{m}^{3}$, logo o GN chegava no Araripe por $\mathrm{R} \$ 1,96 / \mathrm{m}^{3}$. Logo o custo com GN seria de $\mathrm{R} \$ 45,08 /$ ton de gesso, o que seria absolutamente inviável. Levando em consideração a lenha em toras, onde o consumo é de 0,6 a 1,0 steri por tonelada e o preço da lenha legal está na região por cerca de $\mathrm{R} \$ 34,00 /$ steri, logo o custo de produção com lenha fica entre $\mathrm{R} \$ 20,40$ a $\mathrm{R} \$ 34,00 /$ ton. Sem levar em consideração os custos de manuseio da lenha (tem que ter gente para alimentar o forno) e a manutenção, etc. Este custo na maioria das vezes ainda é minimizado em função da lenha ilegal, que hoje na região ainda responde por cerca de $35 \%$ da lenha consumida.

O Forno Tubular Duplo Rotativo: em 2000, um trabalho de pesquisa foi iniciado por pesquisadores do Laboratório Avançado do Gesso, Departamento de Engenharia Mecânica, Universidade Federal de Pernambuco - que surpreendeu os profissionais que lidam diariamente com a produção de gesso ao apresentarem um equipamento que emprega formas alternativas de energia na calcinação da gipsita: um forno tubular duplo rotativo, produzido em

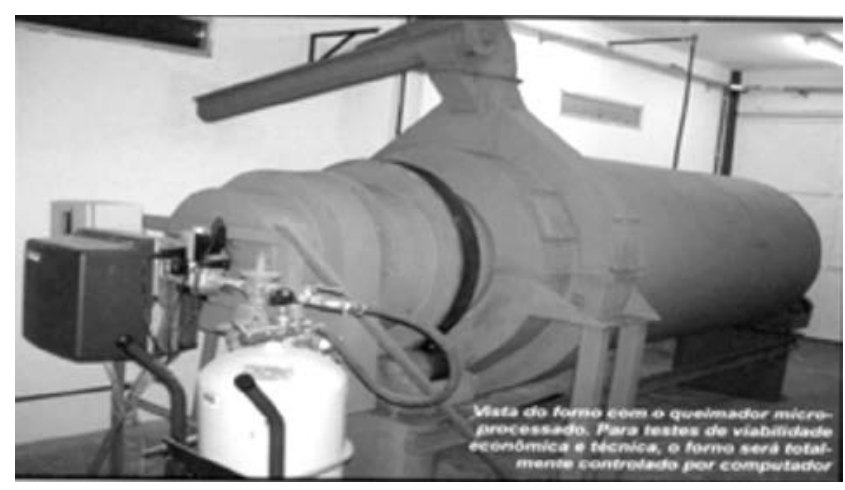

Figura 1: Forno tubular duplo rotativo.

[Figure 1: Double rotating tubular kiln.] escala piloto e que usa gás natural e biocombustíveis em seu abastecimento. Para se ter uma ideia, um forno do tipo "barriga quente" operado a lenha tem sua capacidade térmica estimada em torno de $10 \%$, ou seja, $90 \%$ do calor gerado na queima é dispersado no ambiente, sem ser aproveitado. Em contrapartida, o forno desenvolvido no Laboratório do gesso da UFPE tem eficiência térmica estimada em $90 \%$, um ganho de $80 \%$, portanto. O grande diferencial do equipamento é o seu caráter sustentável. De uma forma geral, a maioria das empresas do Polo Gesseiro não está contabilizando o impacto ambiental causado pela utilização de lenha clandestina na região com fonte energética para queima dos minérios. Algumas indústrias preferem manter os fornos atuais em operação, mesmo sendo conhecidos por sua baixa eficiência térmica. Por outro lado, parte do empresariado começa a se conscientizar e investir em novas tecnologias para a calcinação da gipsita.

O bom desempenho do equipamento ocorre devido ao processo de queima direta a que submete a gipsita, forma mais eficiente de transferência de calor gerada na calcinação. Neste caso, a combustão do gás natural é ideal porque não gera fuligem e reduz substancialmente o impacto ambiental em relação aos demais combustíveis. Já o biodiesel torna-se uma fonte energética interessante, uma vez que é de origem parcialmente renovável. Estudos realizados nos Estados Unidos e na Alemanha indicam que o combustível não emite dióxido de enxofre, gás nocivo à saúde. Outra vantagem do aparelho é a possibilidade de aproveitar melhor a água extraída da gipsita durante a calcinação. Segundo as pesquisas, 15\% dessa água é liberada na atmosfera durante a queima dos minérios nos fornos comuns. No laboratório da Universidade é possível condensar todo o vapor. Neste processo acredita-se que se produza até 110 milhões de litros de água por ano. Estudos em andamento sugerem que o líquido poderia ser destinado a fins mais nobres, como projetos de irrigação e até abastecimento de comunidades sertanejas [7]. O forno tubular duplo rotativo, de queima direta para produção simultânea de gesso e anidrita tem instalado o queimador micro processado de gás natural da Weishaupt, podendo queimar também biocombustíveis, GLP/GN. É um forno que tem a capacidade de produzir em média 30 ton de gesso por dia. Tem dois tubos concêntricos, projetado para produção contínua de gesso puro $\left(\mathrm{CaSO}_{4} \cdot 1 / 2 \mathrm{H}_{2} \mathrm{O}\right)$ e de uma mistura de gesso e anidrita $\left(\mathrm{CaSO}_{4}\right)$, podendo os dois produtos serem produzidos ao mesmo tempo. Devido a sua estrutura e funcionalidade permite durante o curso de matéria-prima em tratamento, em um mesmo ciclo de produção, obter gessos de distintas classes e em proporções facilmente reguláveis. É dividido em duas partes: estrutura fixa e móvel, sendo que a estrutura fixa concentra o maior peso do forno. Em termos tecnológicos, o projeto é pioneiro no País. O forno será controlado via computador e operará por meio da queima de gás natural ou de biocombustíveis, como o biodiesel e o bioetanol empregando-se um queimador micro processado. $\mathrm{O}$ diferencial do forno tubular duplo rotativo está ligado ao 
caráter sustentável do seu funcionamento: a utilização desse tipo de forno é interessante porque dispensa a queima da madeira. Dessa forma, não se intensifica o processo de desertificação. Além disso, como a opção é pelo uso de gás natural/GLP e biocombustíveis, a emissão de poluentes para atmosfera é menor. $\mathrm{O}$ forno está pronto para operar numa experiência inédita, pois em si próprio já traz a enorme vantagem de possuir alta eficiência energética em comparação com os atuais fornos em operação no Polo Gesseiro. A equipe do Laboratório Avançado do Gesso da UFPE tem condições profissionais de gerir uma experiência piloto no Polo Gesseiro tendo o apoio do empresariado local e por que não, do próprio governo do estado? O forno foi construído pela metalúrgica Menkaura de Araripina, que poderia após o sucesso da experiência, construí-los em escala industrial. Tudo aponta para uma experiência de sucesso com resultados muito positivos para a indústria do gesso.

\section{RESULTADOS E DISCUSSÃO}

Abaixo apresentamos algumas tabelas de resultados da experiência de uso do gás natural no Polo Gesseiro do Araripe ilustrando a bom desempenho deste combustível limpo, apesar da baixa eficiência energética dos fornos utilizados no processo.

Tabela IV - Funcionamento com gás natural.

[Table IV - Working with natural gas.]

\begin{tabular}{|c|c|c|c|c|c|c|c|c|}
\hline \multirow[b]{2}{*}{ Data } & \multirow{2}{*}{$\begin{array}{l}\text { Consumo/Bar } \\
\text { Manômetro do } \\
\text { caminhão }\end{array}$} & \multirow[b]{2}{*}{$\begin{array}{c}\text { Hs de } \\
\text { funcionamento }\end{array}$} & \multirow{2}{*}{ Produção (t) } & \multirow{2}{*}{$\begin{array}{c}\text { Médias } \\
\text { das cargas } \\
\text { em min. } \\
\text { (uma carga= } \\
3,5 \mathrm{t} \text { ) }\end{array}$} & \multicolumn{4}{|c|}{$\mathrm{N}^{\mathrm{o}}$ de caminhões. Pressão de chegada e saída } \\
\hline & & & & & $\begin{array}{l}\text { Data de } \\
\text { início do } \\
\text { consumo }\end{array}$ & $\begin{array}{c}\mathrm{N}^{\mathrm{o}} \text { de } \\
\text { caminhões }\end{array}$ & $\begin{array}{c}\text { Pressão } \\
\text { de chegada }\end{array}$ & $\begin{array}{l}\text { Pressão } \\
\text { de saída }\end{array}$ \\
\hline 25.02 .12 & 70 & 18 & 18,5 & 114,7 & 25.2.12 & $1^{\mathrm{o}}$ & 220 & 20 \\
\hline 26.02 .12 & 130 & 14 & 33,3 & 105,4 & 29.2.12 & $2^{\circ}$ & 210 & 10 \\
\hline 01.03 .12 & 175 & 22,03 & 85,1 & 46,33 & 01.3 .12 & $3^{\circ}$ & 200 & 20 \\
\hline 02.03 .12 & 150 & 22,83 & 103,6 & 42,7 & 03.3 .12 & $4^{\circ}$ & 210 & 0 \\
\hline 03.03 .12 & 115 & 16,03 & 77,7 & 49,27 & 04.3 .12 & $5^{\circ}$ & 200 & 0 \\
\hline 04.03 .12 & 150 & 15,5 & 74 & 40 & 06.3 .12 & $6^{\circ}$ & 200 & 0 \\
\hline 05.03 .12 & 110 & 13,13 & 55,5 & 46,25 & 07.3 .12 & $7^{\circ}$ & 190 & 0 \\
\hline 06.03.12 & 220 & 23,85 & 125,8 & 38,6 & 08.3.12 & $8^{\circ}$ & 200 & \\
\hline 07.03.12 & $\begin{array}{c}\mathbf{1 9 0} \\
\text { Total }=1310\end{array}$ & $\begin{array}{c}\mathbf{2 3 , 7 3} \\
\text { Total }=169,1 \\
\end{array}$ & $\begin{array}{c}\mathbf{1 2 9 , 5} \\
\text { Total }=703\end{array}$ & 37,39 & & & & \\
\hline
\end{tabular}

Baseado na produção do gesso de fundição. (Temperatura de defornamento $165^{\circ} \mathrm{C}$ ). Levando em conta as melhores situaçães que são os dias 6 e 7.03 .2012 ao qual estão marcados em vermelho temos os seguintes cálculos:

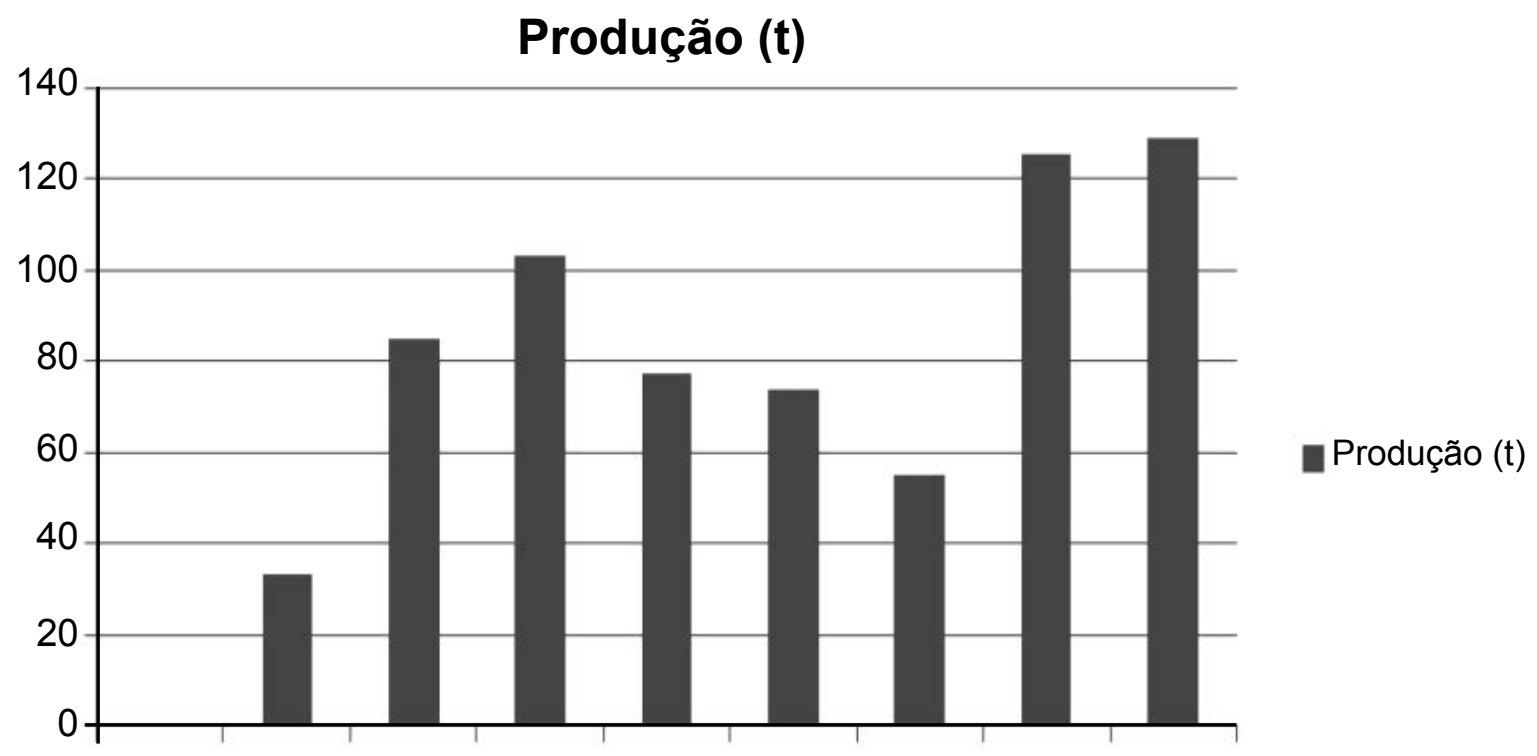

Gráfico referente a tabela IV - Produção (t) /Dia 
Cálculo de consumo do gás, baseado nas informações de que a 1 bar temos $24,6 \mathrm{~m}^{3}$ de gás GNC.

Cal. Com a produção do Dia 06.03.12

220 Bar * 24,6 = 5412 $\mathrm{m}^{3}$

Produção $=125,8 \mathrm{t}$

Então temos $5412 \mathrm{~m}^{3} / 125,8 \mathrm{t}=43,02 \mathrm{~m}^{3} / \mathrm{t}$ de gesso.

Preço do gás à $\mathrm{R} \$ 1,30$

$43,02 * 1,30=\mathrm{R} \$ 55,926$ de gás $/ \mathrm{t}$ de gesso.
Cal. Com a produção do Dia 07.03.12

190 Bar * 24,6 = $4674 \mathrm{~m}^{3}$

Produção $129,5 \mathrm{t}$

Então temos $4674 \mathrm{~m}^{3} / 129,5 \mathrm{t}=36,09 \mathrm{~m}^{3} / \mathrm{t}$ de gesso.

Preço do gás à $\mathrm{R} \$ 1,30$

$36,09 * 1,30=\mathrm{R} \$ 46,917$ de gás / $\mathrm{t}$ gesso.

Cálculo de consumo do gás, baseado nas informações de que a 1 bar temos $25 \mathrm{~m}^{3}$ de gás GNC

Cal. Com a produção do Dia 06.03.12

$220 \mathrm{Bar} * 25=5500 \mathrm{~m}^{3}$

Produção $=125,8 \mathrm{t}$

Então $5500 \mathrm{~m}^{3} / 125,8 \mathrm{t}=43,72 \mathrm{~m}^{3} / \mathrm{t}$ de gesso.

Preço do gás à $\mathrm{R} \$ 1,30$

$43,72 * 1,30=\mathrm{R} \$ 56,836$ de gás $/ \mathrm{t}$ de gesso.
Cal. Com a produção do Dia 07.03.12

$190 \mathrm{Bar} * 25=4750 \mathrm{~m}^{3}$

Produção $=129,5 \mathrm{t}$

Então $4750 \mathrm{~m}^{3} / 129,5 \mathrm{t}=36,68 \mathrm{~m}^{3} / \mathrm{t}$ de gesso.

Preço do gás à $\mathrm{R} \$ 1,30$

$36,68 * 1,30=\mathrm{R} \$ 47,684$ de gás $/ \mathrm{t}$ de gesso.
Cal. Com a Produção do Dia 06.03.12

220 Bar * $18=3960 \mathrm{~m}^{3}$

Produção $=125,8 \mathrm{t}$

Então $3960 \mathrm{~m}^{3} / 125,8 \mathrm{t}=31,47 \mathrm{~m}^{3} / \mathrm{t}$ de gesso.

Preço do gás à $\mathrm{R} \$ 1,30$

$31,47 * 1,30=\mathrm{R} \$ 40,911$ de gás $/ \mathrm{t}$ de gesso.

1 bar temos $18 \mathrm{~m}^{3}$ de gás GNC

Cálculo de consumo do gás, baseado nas informações de que a 1 bar temos $22,6 \mathrm{~m}^{3}$ de gás GNC

Cal. Com a produção do Dia 06.03.12

220 Bar * 22,6 $=4972 \mathrm{~m}^{3}$

Produção $=125,8 \mathrm{t}$

Então $4972 \mathrm{~m}^{3} / 125,8 \mathrm{t}=39,52 \mathrm{~m}^{3} / \mathrm{t}$ de gesso.

Preço do gás à $\mathrm{R} \$ 1,30$

$39,52 * 1,30=\mathrm{R} \$ 51,379$ de gás $/ \mathrm{t}$ de gesso.
Cal. Com a produção do Dia 06.03.12

190 Bar * $18=3420 \mathrm{~m}^{3}$

Produção $=125,8 \mathrm{t}$

Então $3420 \mathrm{~m}^{3} / 125,8 \mathrm{t}=27,186 \mathrm{~m}^{3} / \mathrm{t}$ de gesso.

Preço do gás à $\mathrm{R} \$ 1,30$

$27,186 * 1,30=\mathrm{R} \$ 35,341$ de gás $/ \mathrm{t}$ de gesso.

\section{Observação:}

Temperatura de gases antes do exaustor de fumaça. 06.03.12 Temp. média $200{ }^{\circ} \mathrm{C}$

Temperatura da saída da fornalha para o trocador de calor 06.03 .12 Temp. média $740{ }^{\circ} \mathrm{C}$

Temperatura de gases antes do exaustor de fumaça. 06.03.12 Temp. média $200{ }^{\circ} \mathrm{C}$

Temperatura da saída da fornalha para o trocador de calor 07.03 .12 Temp. média $720{ }^{\circ} \mathrm{C}$

Tabela $\mathrm{V}$ - Consumo de gás natural por carreta.

[Table V - Natural gas consumption per trailer.]

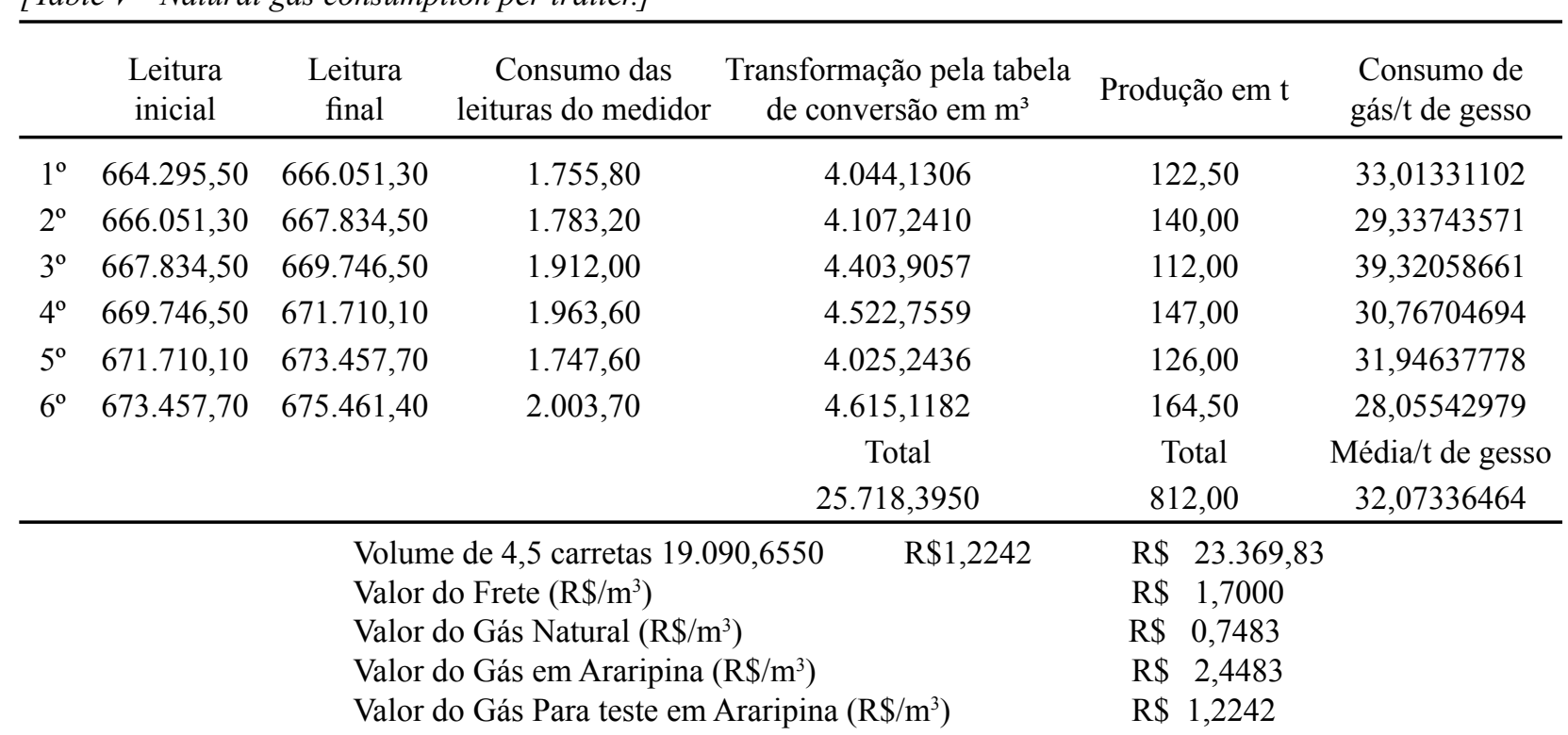




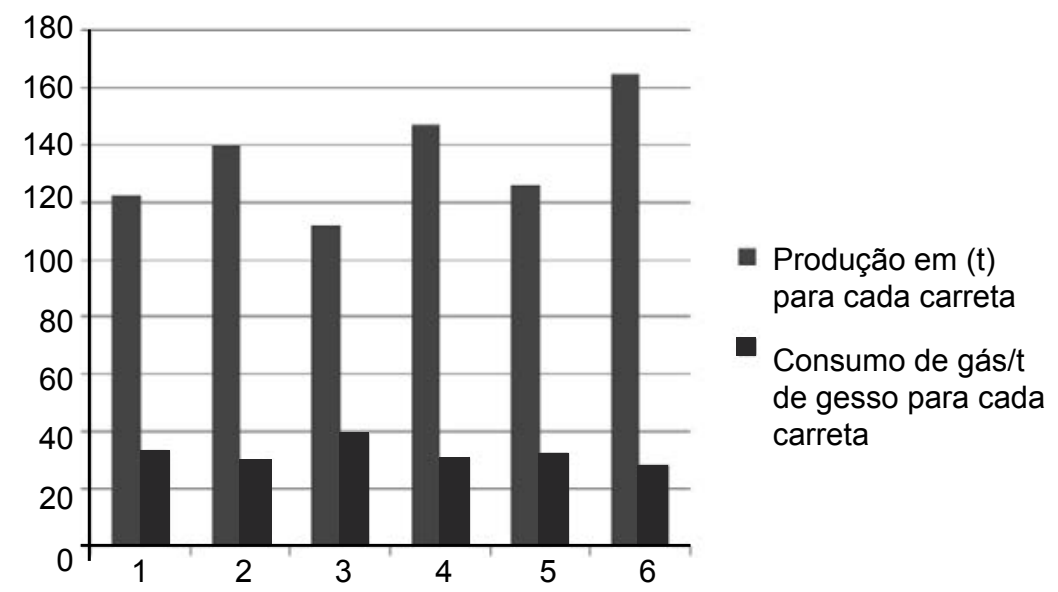

Gráfico referente a tabela V - Consumo de gás $\left(\mathrm{m}^{3}\right) / \mathrm{t}$ de gesso para as seis carretas

Tabela VI - Consumo de gás natural por dia de produção.

[Table VI - Consumption of gas per day production.]

\begin{tabular}{ccccccc}
\hline Data & Leitura inicial & Leitura final & $\begin{array}{c}\text { Consumo das } \\
\text { leituras do medidor } \\
\text { de vazão }\end{array}$ & $\begin{array}{c}\text { Transformação pela } \\
\text { tabela de conversão } \\
\text { em m }\end{array}$ & $\begin{array}{c}\text { Produção em } \\
\text { toneladas }\end{array}$ & $\begin{array}{c}\text { Consumo } \\
\text { gás/t de gesso }\end{array}$ \\
\hline 26.3 .12 & $664.295,50$ & $665.493,50$ & $1.198,00$ & $2.759,3510$ & 80,50 & 34,27765217 \\
27.3 .12 & $665.493,50$ & $666.605,10$ & $1.111,60$ & $2.560,3460$ & 84,00 & 30,48030952 \\
28.3 .12 & $666.605,10$ & $667.634,50$ & $1.029,40$ & $2.371,0149$ & 80,50 & 29,45360124 \\
29.3 .12 & $667.634,50$ & $668.956,50$ & $1.322,00$ & $3.044,9599$ & 84,00 & 36,24952262 \\
30.3 .12 & $668.956,50$ & $670.364,70$ & $1.408,20$ & $3.243,5042$ & 94,50 & 34,32279577 \\
31.3 .12 & $670.364,70$ & $671.610,70$ & $1.246,00$ & $2.869,9093$ & 91,00 & 31,53746484 \\
01.4 .12 & $671.610,70$ & $672.774,90$ & $1.164,20$ & $2.681,4995$ & 87,50 & 30,64570857 \\
02.4 .12 & $672.774,90$ & $673.971,40$ & $1.196,50$ & $2.755,8960$ & 98,00 & 28,12138776 \\
03.4 .12 & $673.971,40$ & $674.589,90$ & 618,50 & $1.424,5898$ & 45,50 & 31,30966593 \\
04.4 .12 & $674.589,90$ & $675.900,10$ & $1.310,20$ & $3.017,7810$ & 93,00 & 32,44925806 \\
05.4 .12 & $675.900,10$ & $677.041,20$ & $1.141,10$ & $2.628,2933$ & 77,50 & 33,91346194 \\
& & & & Total & Total & Média/t \\
de
\end{tabular}

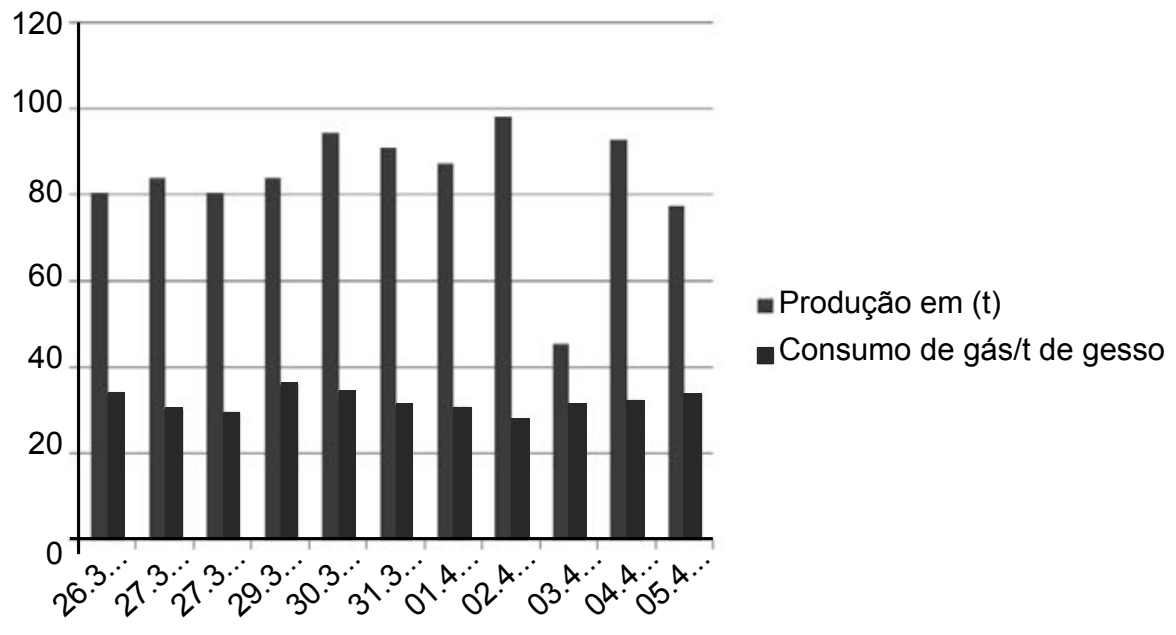


Foram feitos testes com os $9.000 \mathrm{~kg}$ de gás GLP na IGE nas mesmas condições que teve o gás GN. Mas diante dos resultados não satisfatórios decidiu-se não mais continuar com os mesmos. Durante todos os testes alguns técnicos, acompanharam e fizeram varias regulagens. Em conjunto decidiu-se fazer o segundo cenário, que seria a diminuição da fornalha, sugerida pelo gerente industrial da IGE, consistindo apenas em elevar o piso da fornalha. Dia 23.04.12 consumiu 1.044,61 kg de GLP, Dia 24.04.12 consumiu $1.608 \mathrm{~kg}$ de GLP, Dia 25.04.12 consumiu $392,1 \mathrm{~kg}$ GLP, Total de $3.044,71 \mathrm{~kg}$ GLP. A média dos três dias de teste com o gás GLP foi de R $\$ 58,886 /$ t de gesso, colocando o preço a $\mathrm{R} \$ 2,08$. Os testes continuaram até setembro/2012 e foram conseguidos resultados bem melhores: $\mathrm{R} \$ 39,78 / \mathrm{t}$ de gesso, $\mathrm{R} \$ 33,16 / \mathrm{t}$ de gesso entre outros.

\section{CONCLUSÕES}

Podemos observar em todos os fatos aqui relatados que há uma imensa disposição para uma real mudança da matriz energética no Polo Gesseiro do Araripe, uma preocupação mais do que necessária, imprescindível, de preservação da caatinga já tão enormemente devastada. $\mathrm{O}$ fato é imutável - a devastação ambiental da região - mas o propósito do empresariado local está firmemente focado numa indústria progressista, porém que não interfira na sustentabilidade ambiental local. Vemos que empresas como a Copergás investiram numa conversão do forno da empresa New Gipso, conseguindo aumentos na produtividade, com a diminuição do tempo de calcinação de metade, para a mesma quantidade sendo calcinada usando lenha como combustível. São evidentes os benefícios acarretados com esta mudança e só para listar alguns poderíamos elencar a preservação ambiental, o aumento da quantidade de gesso produzido com o gás, devido ao seu maior poder calorífico, o menor custo final do gesso devido ao gás ter chegado $30 \%$ mais barato do que o equivalente á madeira, o uso do processo de queima direta por ser o gás natural limpo o que acelera o tempo de calcinação da gipsita e evita a sua contaminação, ao contrário do que acontece com a lenha e o coque, que precisam ser queimados fora do forno (queima indireta) [8]. Com relação ao uso dos combustíveis disponíveis no mercado, e ao que foi até aqui apresentado, podemos reafirmar que o gás natural, somente se tornará viável a partir de um gasoduto entre Caruaru e Araripina, com cerca de $552 \mathrm{~km}$ de extensão. Seria o ideal para a produção de gesso, tendo para isso, garantia de fornecimento, no entanto um empreendimento de custo muitíssimo elevado. O seu uso ideal seria a partir de fornos contínuos de queima direta. O APL do gesso teria que renovar todos os fornos de queima indireta, e a energia aplicada no objetivo da desidratação da gipsita de forma eficiente teria o mínimo de perdas [9]. Estudos preliminares de utilização do Gás Natural em fornos rotativos de produção de gesso demonstraram vantagens técnica e econômica desse tipo de combustível gasoso em relação ao GLP, quando operando em condições otimizadas. Entretanto, importantes pontos críticos foram detectados através de contatos com empresários do Pólo Gesseiro destacando-se: - dificuldades de uso do GN como fonte de calor para o processo, em razão da não existência de gasodutos nas proximidades do Pólo; - incerteza de implantação de um gasoduto para suprir o Pólo Gesseiro com GN; - em caso de se construir um gasoduto, existem dúvidas quanto a uma política de preços para manter o GN dentro de uma faixa que permita caracterizá-lo como responsável pela obtenção do gesso como um produto competitivo [10]. O Gás GLP seria uma segunda opção, também para queima direta. O maior empecilho para seu uso são as altas taxas de impostos cobrados e a variação dos preços dos derivados de petróleo. $\mathrm{O}$ uso da biomassa como fonte renovável de combustível seria dependente de reflorestamento para atender ao APL do Gesso como um todo e dar segurança na provisão contínua de combustível. Os projetos de manejo sustentável não suportam a demanda do setor. O problema fundiário dificulta a aprovação de projetos, além da burocracia. Pode ser o futuro do APL também em relação a sustentabilidade. $O$ trabalho apresentado no $6^{\circ}$ Cong. Bras. de P\&D em Petróleo e Gás em 2011 envolve o estudo do processo de produção de gesso beta em um forno piloto rotativo contínuo de contato direto, semelhante aos existentes no Polo Gesseiro, disponível no

Tabela VII - Resultados das características físico-químicas e mecânicas das amostras.

[Table VII - Results of physicochemical characteristics and mechanical properties of samples.]

\begin{tabular}{ccccccc}
\hline Amostras & $\begin{array}{c}\text { Grau de } \\
\text { hidratação }(\%)\end{array}$ & $\begin{array}{c}\text { Dureza } \\
(\mathrm{N} / \mathrm{mm})\end{array}$ & $\begin{array}{c}\text { Massa Utilitária } \\
(\mathrm{MPa})\end{array}$ & $\begin{array}{c}\text { Tempo de } \\
\text { pega inicial } \\
(\mathrm{min})\end{array}$ & $\begin{array}{c}\text { Tempo de } \\
\text { pega final } \\
(\mathrm{min})\end{array}$ & $\begin{array}{c}\text { Resistência } \\
\text { mecânica }\left(\mathrm{kg} / \mathrm{m}^{3}\right)\end{array}$ \\
\hline 1 & 6,0 & 60 & 932,2 & 5,9 & 28,3 & 22,6 \\
2 & 6,0 & 59 & 960,0 & 8,3 & 22,5 & 26,8 \\
3 & 6,0 & 58 & 910,3 & 6,1 & 22,6 & 22,2 \\
4 & 5,8 & 60 & 927,5 & 7,2 & 28,7 & 25,8 \\
5 & 5,9 & 58 & 940,0 & 6,5 & 24,1 & 26,0 \\
6 & 6,1 & 62 & 965,2 & 8,5 & 29,0 & 27,4 \\
Norma & $4,5 \leq \mathrm{X} \leq 6,3$ & $\mathrm{X}>30$ & $\mathrm{X}>700$ & $4 \leq \mathrm{X} \leq 10$ & $20 \leq \mathrm{X} \leq 45$ & $\mathrm{X}>8,4$ \\
\hline
\end{tabular}


Departamento de Engenharia Química da UFPE, utilizando o gás natural como combustível. Para isso, o material produzido pelo forno foi analisado, verificando se o mesmo se enquadra segundo a Norma NBR 13207, que determina valores das principais características do gesso produzido no Brasil, verificando assim como a adoção do gás natural como combustível afetará a qualidade do gesso produzido. Após a realização dos experimentos, foram coletadas 6 amostras, as quais deveriam ser analisadas segundo o grau de hidratação, dureza, massa unitária, resistência mecânica e tempo de pega inicial e final, tendo como referência a norma NBR 13207, que associa valores dessas grandezas a qualidade do gesso.Os resultados das medições do material formado são listados na Tabela VII [11].

Segundo a norma NBR 13207, o grau de hidratação para um gesso de qualidade deve estar entre $4,2 \%$ e $6,2 \%$, abaixo de $4,2 \%$, gipsita não foi ainda convertida em gesso, já para valores acima de $6,2 \%$ ocorre à formação de anidrita II, ou seja, parte do material convertido foi transformada em gesso e outra parte em anidrita II, interferindo assim na qualidade do gesso final. As amostras apresentaram valores de conversão entre $97 \%$ e $94 \%$, ou seja, grande parte da gipsita foi convertida em gesso. Todas as amostras atingiram um valor acima do valor mínimo exigido pela NBR 13207, ou seja, o estudo do processo de calcinação da gipsita em um forno piloto rotativo contínuo a contato direto funcionando com gás natural como combustível, e a análise das propriedades físico-químicas e mecânicas do gesso obtido em comparação com a norma técnica NBR13207, permitiu concluir que todas as amostras analisadas apresentaram valores de grau de hidratação, massa unitária, resistência mecânica, dureza e tempo de pega inicial e final que respondam aos padrões exigidos pelas normas referentes à qualidade de gesso. Dessa forma, podemos concluir que a produção de gesso através da utilização de gás natural como combustível enquadra o material produzido dentro da norma NBR13207, que define o padrão de qualidade do gesso no Brasil. Dessa forma, pode-se obter um gesso de qualidade e respondendo às normas técnicas em vigor, com conseqüente redução dos desperdícios durante a produção (altas conversões da gipsita), como também proporcionando uma limitação ao impacto ambiental, já que o gás natural é considerado um combustível mais limpo do que os que são utilizados pela maioria das empresas no Polo Gesseiro do Araripe. Outra importante redução no impacto ambiental se deve a diminuição do processo de desmatamento para produção de lenha como combustível. Além disso, a garantia da qualidade do gesso produzido com gás natural traz perspectivas de mudança e crescimento na região do Araripe, dado que as empresas da região terão um melhor controle da qualidade do gesso e garantia de insumo energético, fato que não ocorre com a utilização de lenha combustível [12]. Em 2011 o primeiro passo para solucionar o problema da matriz energética do Araripe foi dado. É preciso não interromper o processo que trará vantagens inumeráveis a todo o empresariado do Polo Gesseiro do Araripe, bem estar aos moradores da região e benefícios inenarráveis para o meio ambiente local. $\mathrm{O}$ grande desafio do laboratório é agora colocar os fornos em operação nas empresas que integram o Polo Gesseiro do Araripe, em Pernambuco. Conversas e discussões sobre esta possibilidade têm acontecido com o Sr. J. Inojosa Filho que, sensibilizado com o enorme problema da matriz energética do Polo Gesseiro, disponibilizou toda a infraestrutura da Supergesso para realizar os testes que se fizerem necessários com o gás natural e o GLP no FTDR, numa iniciativa inédita rumo ao desenvolvimento sustentável do Polo. Governo e iniciativa privada devem se unir nesta direção, pois em todo este processo, com certeza o maior beneficiado será o Brasil.

\section{REFERÊNCIAS}

[1] K. A. R. Ismail, F. A. de M. Lino, J. C. Charamba, A. R. M. Primo, J. R. H. Guerrero, A. Shinohara, C. K. Suzuki, "Os Combustíveis Alternativos Líquidos e Gasosos", Ed do Autor, Campinas, SP (2010) 61.

[2] F. M. C. Oliveira, L. E. P. Borges, E. B. Melo, M. L. S. C. Barros, Características Mineralógicas e Cristalográficas da Gipsita do Araripe, Holos 5 (2012) 71.

[3] M. L. S. C. Munhoz, A. Renofio, XXVII Enc. Nac. Eng. Prod., Uso da gipsita na construção civil e adequação para A P+L, Foz do Iguaçu, PR (2007) 3.

[4] S. M. S. de Araújo, O Polo Gesseiro do Araripe: Unidades Geo-Ambientaise Impactos da Mineração, Tese Dr. 320/2004, Inst. Geoci. UNICAMP, Campinas, SP (2004) 115.

[5] L. L. N. Guarieiro, P. C. Vasconcellos, M. C. Solci, Ver. Virtual Química 3, 5 (2011) 434.

[6] F. A. Nodari, RIMA - Relatório de Impacto Ambiental Ferrovia Transnordestina - DNIT (2004) 143p.

[7] S. Thais, Rev. Gesso \& Cia, Ano 2, N. 8 (2009) 16.

[8] M. Benachour, P. L. S. Santos, Gesso: aplicação na construção civil, SEBRAE, Recife, PE (2008) 25.

[9] C. A. M. Baltar, F. F. Bastos, L. E. P. Borges, in: Anais Enc. Nac. Trat. Min. Metal. Extrat., Variedades Mineralógicas e Processos Utilizados na Produção dos Diferentes Tipos de Gesso, Florianópolis, SC (2004) 254.

[10] V. A. dos Santos, L. dos S. Peres, M. Benachour, Viabilização Técnico-Econômica do Processo de Produção de Gesso em Forno de Calcinação com Uso de Gás Natural, FINEP/PETROBRÁS/COPERGÁS/UFPE/ UNICAP/ITEP/ SENAI RT-P051-005-GESS0-GN, Recife, PE (2004) 206.

[11] D. E. S. Cavalcanti, R. A. D. P. Melo, D. C. P. Melo, R. A. M. Souza, M. Benachour, $6^{\circ}$ Cong. Bras. Pesq. Desenv. Petróleo Gás, Assoc. Bras. P\&D Petr. Gás, Florianópolis, SC (2011) 3. "Avaliação da Qualidade de Gesso Beta produzido em Forno Rotativo Contínuo usando o Gás Natural como Combustível".

[12] F. C. B. Campello, G. Leal Júnior, J. A. da Silva, R. C. B. Campello, Avaliação dos Recursos Florestais da Área de Proteção Ambiental Chapada do Araripe, Crato, Ministério do Meio Ambiente e Instituto Brasileiro do Meio Ambiente e dos Recursos Naturais Renováveis, Relatório Técnico (2000) $49 \mathrm{p}$.

(Rec. 21/09/2013, Rev. 14/11/2013, Ac. 25/01/2014) 